\section{Lo efímero es arquitectura}

The ephemeral is architecture

Gabriela de la Piedra
ABSTRACT The tinglado number 2 was built in 1911 as part of a set
of 6 buildings, closed still lifes with a steel structure that were used to store the merchandise that arrived
at the port; Modernist building with a patrimonial and strategic interest firm RELLAM has carried out ephemeral, elegant and consistent intervention that allows this work square of views and actions between the sea and the city awaiting the fin restoration. Key Words Tinglado,
Ephemeral, Heritage, Restoratio Ephemeral, H

figura 1
Tinglado2 2
RELLLAM

(Imagen cortesia de RELLAM

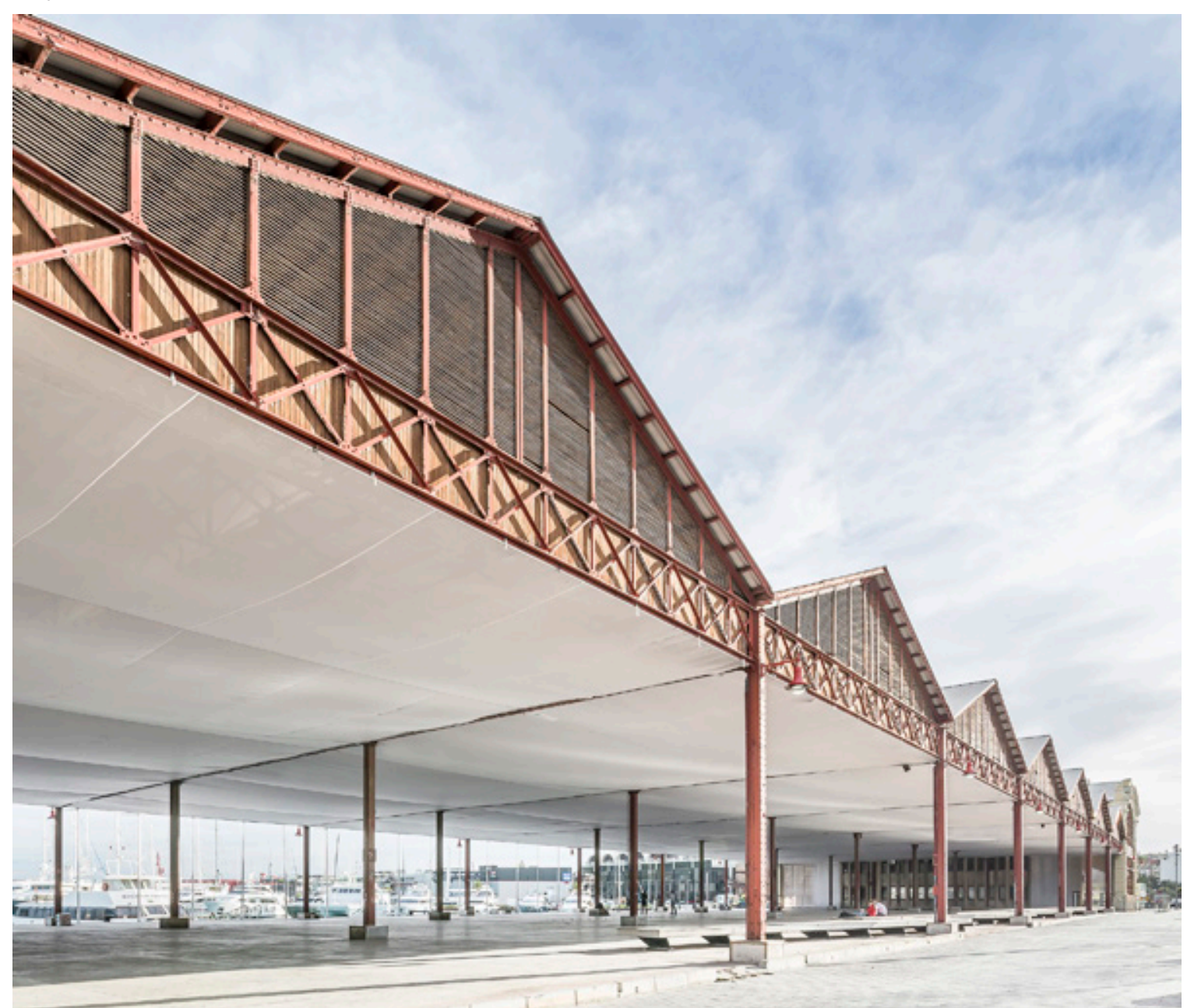

Resumen El tinglado numero 2 fui construido en 1911 como parte de un conjunto de 6 edificios, bodegones cerrados con estructura de acero que fueron utilizados para guardar la mercancía que llegaba a puerto; edificio modernistas con un interés patrimonial y estratégico para la ciudad, después de años de abandono la y consistente que permite que esta obra pueda ser utilizada por todos como una plaza articuladora de vistas y acciones entre el mar y la ciudad a la espera de la restauración definitiva. firma RELLAM ha realizado una intervención efímera, elegante 


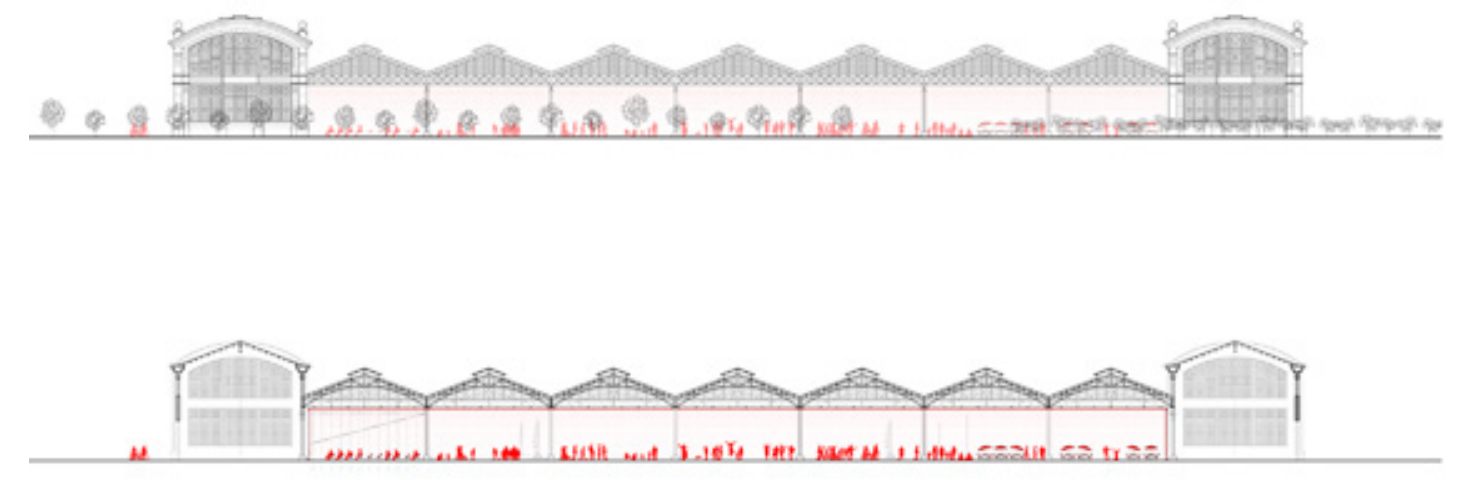

figura 2
Tinglado2 2
REI AM

(Imagen cortesia de RELLAM)

El tinglado número 2 del puerto de Valencia fue construido en el año 1911 por la empresa Maquinista Terrestre y Marítima, proyecto de los ingenieros José María Fuster y Fausto Élio. Esta obra forma parte de un conjunto de construcciones de 6 tinglados distribuidos por el puerto, cuerpos cerrados y simétricos que estaban destinados al almacenaje de mercancía. En 1936, con el estallido de la Guerra Civil española, acontece la destrucción de los tinglados debido a su lugar estratégico para la ciudad. Tras la guerra, en 1940, los ingenieros Justo Vilar y Luciano Yordi Menchaca llevan a cabo la reconstrucción de los tinglados 2, 4 y 5 , ya que fueron los únicos edificios de los 6 iniciales que sobrevivieron los ataques, perdurando hasta el día de hoy. Con esta intervención las construcciones laterales del tinglado 2 pasan a estar abiertas, modificando el ritmo del edificio, el uso y su proporción. En 1984 se lleva a cabo una segunda intervención, tratando de devolverle sus proporciones iniciales y recuperando de alguna manera el aspecto con el que fue concebido. Entre 2007 y 2012, el puerto de Valencia acogió dos ediciones de la American's Cup y el Gran Premio de Fórmula 1, invirtiendo el gobierno de Valencia, por este motivo, en la zona del puerto. Esta fue la última mantención que tendrían los tinglados y luego vendría el abandono.

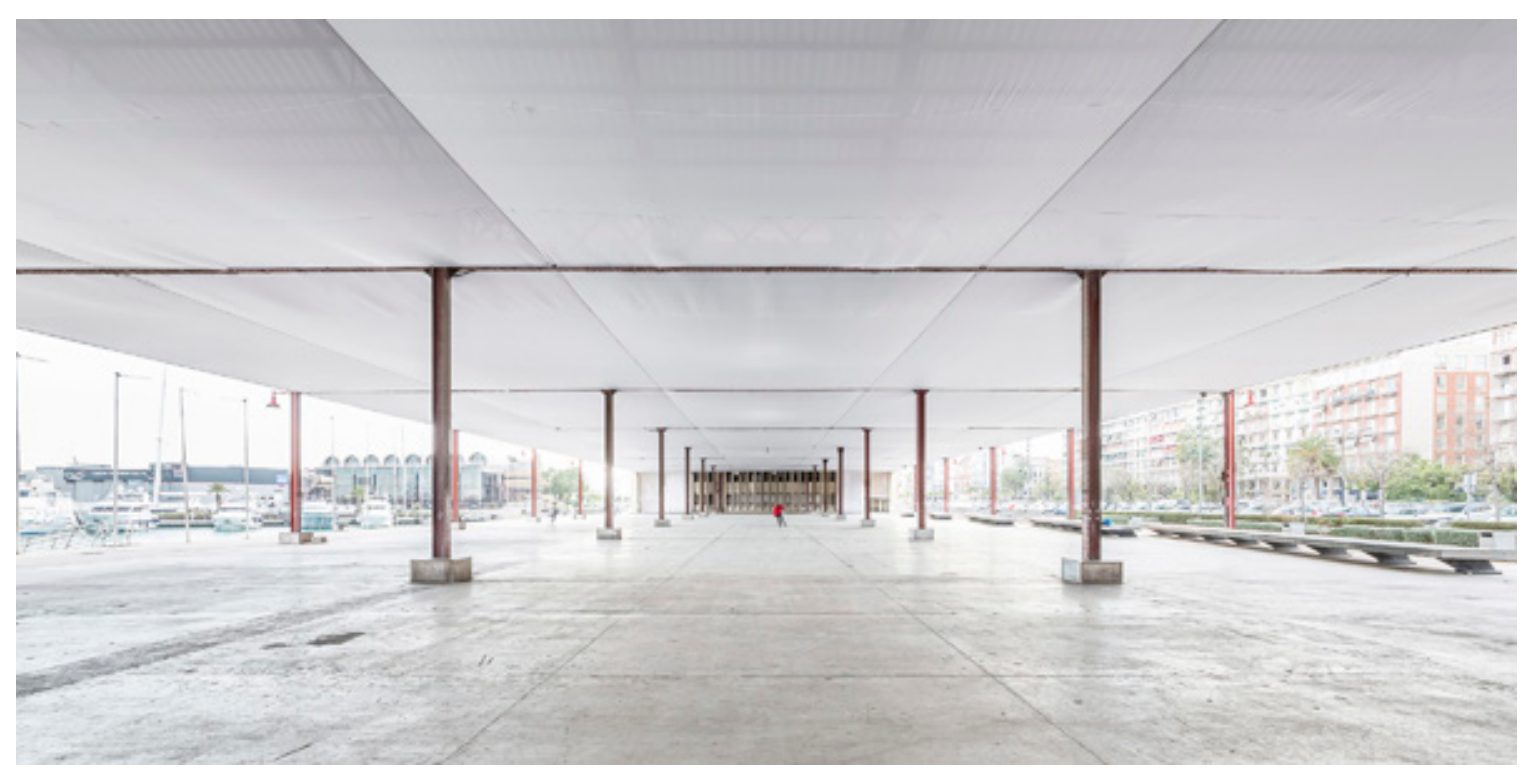

figura 3
Tinglado2

(Imagen cortesía de RELLAM Este bodegón se configura originalmente en una composición clásica, simétrica de tres cuerpos: dos laterales en los extremos en forma de torreón de acceso y en el centro, una sucesión de planos quebrados que salvan grandes luces, cerrados en sus paramentos, permitiendo la entrada de la luz cenital, recordándono para qué fue concebido; esto sobre una estructura de marco rígido de acero.

En espera de su restauración, el tinglado $\mathrm{N}^{\circ} 2$ fue intervenido de emergencia en el año 2017 por petición de la marina de Valencia, para poder ser utilizado como un espacio público, a la oficina de arquitectos RELLAM, cuyo equipo está compuesto por Andrea Gimeno, Lluís Liñán y Xevi Lluch. La petición no era tarea fácil: trabajar en un edificio patrimonial de más de cien años, los últimos de ellos, abandonado y cuya estructura sufre fuertemente de corrosión. Lo anterior, sumado a un presupuesto reducido, hizo que esta tarea pareciera titánica. Los arquitectos manifiestan que el presupuesto sirvió "para tapar agujeros, para estabilizar los cuerpos laterales y para cubrir con una malla ignífuga de poliéster la superficie interior del edificio con la intención de minimizar el impacto de las aves sobre los elementos portantes", logrando el fin específico solicitado, proteger un edificio para así poder entregar una plaza techada a la comunidad.

Visitar la obra y leer lo que dicen los arquitectos a cargo nos da pie a una reflexión interesante, de la cual emerge una pregunta inicial: ¿es esta intervención de emergencia una obra de arquitectura? Sabemos que la arquitectura es el arte o la técnica de proyectar, en donde proyectar es pensar un elemento diseñándolo cabo; ante esto, la respuesta inmediata es "iisí!!, es una obra de arquitectura”; entonces, si la respuesta es fácil la pregunta que debiéramos hacernos es: ¿qué hace interesante una obra de arquitectura de esta magnitud que no perdurará en el tiempo?

El resultado de esta intervención transitoria y de emergencia que debía ser de desmontaje fácil a la espera de la definitiva, parece simple a la vista, casi efímera. Fue magnifico, fue más allá de lo esperado por los propios arquitectos y se puede analizar en dos sentidos: el primero, mirándolo desde lo arquitectónico y su impacto en la historia de la ciudad, lograron darle prestancia al edificio, respetando su carácter patrimonial industrial, poniendo en valor la elegancia que lleva un edifico modernista como este, logrando cambiar la atmósfera del lugar tanto que conmueve en la gráficamente, estableciendo el modo de llevarla a simpleza, entregando un espacio de calidad a la ciudad; el segundo, desde la mirada del que lo habita desde la mirada urbana....aquel edificio que estaba destinado a ser un almacén, se vacía para volver a ser llenado esta vez de personas, de actos, abriendo el frente marítimo al uso de los habitantes, generando una integración urbana de la costa con la ciudad, casi como un ente articulado de vistas y movimientos, donde la intervención, más allá de ser de emergencia y efímera, otorga esa continuidad de vista que permite que el edificio desaparezca y solo quede un marco al mar pasando de modernista a moderno recordándonos aquellos espacios limpios y continuos característicos de este movimiento.

En definitiva, mi respuesta a la pregunta de fondo sería la simpleza de lo efímero; si emociona, si evoca un recuerdo, es sin lugar a duda arquitectura.

\section{Gabriela de la Piedra}

Escuela de Arquitectura de la universidad Mayor. Arquitecta, Master en historia critica del arte y la Arquitectura, académico asociado y Directora Docente de la Escuela de Arquitectura de la universidad Mayor, presidenta del comité para las a 